\title{
LA TEATRALIDAD COMO CRÍTICA DE LA MODERNIDAD
}

\section{Óscar Cornago CSIC-Madrid}

\begin{abstract}
El teatro nos sitúa en pleno centro de lo que es religioso-político: en la cuestión de la ausencia, en la negatividad, en el nihilismo, diría Nietzsche, por lo tanto en la cuestión del poder. Una teoría de los signos teatrales, una práctica (dramaturgia, escenificación, interpretación, arquitectura) de los signos teatrales se basa en la aceptación del nihilismo inherente a la representación, e incluso lo refuerzan.
\end{abstract}

Lyotard (1973: 89)

Aunque en las últimas décadas han aumentado de forma considerable los estudios acerca del hecho de la representación y sus modos de funcionamiento, la teatralidad, como una de sus dimensiones fundamentales, está aún lejos de haber alcanzado la difusión y el consenso que merece un hecho tan complejo y presente al mismo tiempo en la articulación de toda cultura y especialmente de la Modernidad ${ }^{1}$. En términos generales, los estudios sobre teatralidad se pueden dividir entre aquellos que abogan por una comprensión amplia de este fenómeno y quienes lo piensan como algo privativo del medio teatral (Taylor y Villegas 1994; Fischer-Lichte 1995; Villegas 1996; Rozik 2000; Féral 2003; Davis y Postlewait 2003). Sin ánimo de exclusión de las aportaciones derivadas de unos y otros enfoques, lo cierto es que el calificativo de "teatral" ha gozado de una enorme difusión, no restringida al campo de lo escénico. En cualquier caso, ya sea entendido como un concepto exclusivamente escénico, ya sea como una condición que recubre todo lo social, la difusión de este término no se corresponde con una conciencia clara de qué puede entenderse por teatralidad, de qué significa y cómo funciona exactamente, de por qué hay cosas que parecen más teatrales que otras, de por qué, finalmente, en una sociedad en la que los niveles

1.- Este estudio se enmarca dentro del proyecto de investigación "L a teatralidad como paradigma de la Modernidad: análisis comparativo de los sistemas estéticos en el siglo XX (desde 1880)", financiado por el programa Ramón y Cajal (2001-2006) del Ministerio de Educación y Ciencia. 


\section{LA TEATRALIDAD COMO CRÍTICA DE LA MODERNIDAD}

de teatralidad han alcanzado una extraordinaria complejidad dicho concepto ha quedado reducido con frecuencia a un calificativo despectivo que alude a algo que no es verdadero y un hecho de difícil delimitación. Posiblemente, su amplia difusión en campos tan diversos, como el arte, la etnografía, la sociología, la sicología y la lingüística entre otros, hace difícil esta delimitación de una idea que, aunque solo sea por su amplia utilización, hemos de pensar que afecta a algún punto vital de la escena histórica actual.

La identificación de lo teatral con algo engañoso, algo que no es verdadero, podría explicar quizá que se preste menos atención a un fenómeno que parece que no remite a una verdad, sino que más bien ostenta su falsedad frente a ella, a diferencia de las buenas representaciones, las copias legítimas, como diría Deleuze (1969: 332), que son aquellas que sí conducen directamente al original, al padre, a la verdad. La teatralidad, como el simulacro al que se refiere el filósofo francés, sería una copia degradada que nos llama la atención sobre el componente artificioso, sobre el ejercicio de puesta en escena y sustitución que oculta toda representación. Ahora bien, estos fenómenos, como el ejercicio de la puesta en escena, el énfasis en lo artificioso y el juego de sustituciones entre originales y copias, entre modelos y copias, están alojados en el corazón de la Modernidad, las potencias de lo falso, de ahí la necesaria actualidad de este concepto de teatralidad como enfoque crítico hacia una cultura que lo ha llevado a su grado más alto de rentabilización.

Aunque el concepto fue utilizado en las primeras décadas y sobre todo en el entorno cultural del Este, comenzando por aquel estudio de Nicolaj Evreinov, ya en 1908, El teatro en la vida, es a partir de los sesenta con la recuperación del Estructuralismo y el desarrollo de la semiótica, que va a ser estudiado de manera sistemática, adoptando en ocasiones como punto de comparación la idea de "literariedad", es decir, el estudio de aquellas propiedades que convierten un texto en un producto literario. Siguiendo este paralelismo, la teatralidad debía ser lo específico del teatro, aquellos rasgos que convicrten una representación en teatro. Este accrcamiento nos permite avanzar en el pensamiento de este concepto, sin embargo su desarrollo no ha surtido los efectos que se podían esperar. La relación que sc establece entre texto y literatura, por un lado, y representación y teatro, por otro, no forma una proporción directa; lo que ha hecho que ambas perspectivas de estudio hayan abierto horizontes distintos. $\mathrm{Y}$ el elemento fundamental que diferencia ambas realidades, el texto y la representación escénica, es la tan diversa materialidad que subyace a una y otra: la palabra escrita, por un lado, y el cuerpo y los objetos, la acción, el espacio y la palabra dicha, por otro; materialidades que remiten a su vez a procesos de recepción que ponen en marcha mecanismos síquicos también diversos: la lectura frente a la percepción sensorial.

La pregunta acerca de la literariedad, la necesidad de analizar lo específico del lenguaje literario, ha funcionado como motor de las Ciencias Humanas durante el siglo XX; tratando de responder a esta pregunta se han desarrollado disciplinas tan características de las Humanidades como la Teoría de la Literatura, al tiempo que la Lingüística del texto conocía un enorme impulso. La aplicación de esta cuestión al género narrativo en los años sesenta dio lugar a la narratología, y al amparo de ésta se siguió desarrollando el concepto de "texto", una idea que vía la semiótica será traspolada a otras realidades no literarias, como el "texto teatral/espectacular", el "texto cinematográfico" o el "texto cultural".

El cstudio de la teatralidad chocó pronto con circunstancias específicas distintas de las definidas por el fenómeno de la literariedad. Mientras que este último se podía acotar dentro del campo de lo literario, es decir, de los textos, la idea de teatralidad saltaba con facilidad, de manera legítima o no, a otros campos no específicamente teatrales, y de ahí la dificultad en cuanto a su definición y modos de funcionamiento. Las grandes urbes, el surgimiento de las masas ligado a la revolución industrial, la sociedad de consumo y los adelantos de los medios de comunicación, han potenciado los niveles de teatralidad. El número de escenarios donde actuar, a los que poder mirar y donde ser visto, ha conocido un abrumador aumento con la proliferación de monitores, cámaras y otros espacios públicos de fácil alcance para grandes públicos. Más allá de que la consideración de lo teatral como algo exclusivo del ámbito artístico de la escena, es innegable que en cada cultura 


\section{ÓSCAR CORNAGO}

existen sentidos diversos de la teatralidad que se juegan en ámbitos de la realidad, tanto sociales como privados, políticos o sicológicos, muy dispares.

De otro lado, las transformaciones en la esfera de lo social y tecnológico han ido en paralelo al desarrollo de la subjetividad moderna y el debate sobre las identidades individuales y colectivas, sicológicas o históricas, que han provocado la necesidad también de su puesta en escena, de su exhibición ante los demás; lo cual ha incidido asimismo en el auge de las estrategias de teatralidad en la sociedad moderna. En última instancia, diríamos que toda puesta en escena hace visibles unas cosas y oculta otras, y esto, como nos recuerda Lyotard, es una estrategia de poder, de afianzamiento de unos valores o resistencia contra otros dominantes. La escenificación supone un modo de ordenar la realidad para su representación, de jerarquizarla y valorarla en función de una determinada estrategia de poder,

[...] no es una actividad "artística", es un proceso general que afecta a todos los campos de actividad, proceso profundamente inconsciente de separación, de exclusiones y desapariciones [...] instituir entre una y otra región una relación de representación o de dobleidad, acompañada obligatoriamente de una desvalorización relativa de las realidades de escena que entonces ya no son más que representaciones de las realidades de realidad (Lyotard 1973: 59).

La escena teatral se manifiesta como un laboratorio idóneo para estudiar cómo funcionan las estrategias de representación y por tanto de poder en cada cultura, pero esto no debería impedir como defiende el filósofo francés- la aplicación de los resultados de estos análisis a otros hechos no artísticos; $y$ viceversa, la teatralidad inherente a las ceremonias sociales, actos políticos, encuentros populares, así como a la construcción de las identidades y las estrategias de comunicación de los medios de masas, como la radio, el cine, la televisión o Internet, nos ofrecen mecanismos que la escena teatral va a adoptar en cada momento, aunque con intereses diversos; no en vano, el teatro es el único medio que, al carecer de un lenguaje exclusivo, ha de tomar sus códigos de aquellos que les propone la cultura en la que se desarrolla. El hecho de que una determinada clase de teatro dé prioridad a las palabras, a las ideas, al cuerpo, a las imágenes o al movimiento dice mucho de esa sociedad. De igual forma, el espacio que ocupa el espectador frente a la escena, su actitud ante la representación, su relación con el actor, su posición distanciada o cercana frente a lo que está viendo son también significativos. Un tipo de programa de televisión como Big Brother, que se ha universalizado con significativa rapidez, nos hace pensar, por ejemplo, en un modo determinado de teatralidad que juega con los límites entre la ficción y lo real, entre lo que es verdad y lo que es mentira, algo por otro lado característico de toda la Modernidad; aunque bien es cierto que estas estrategias pueden ser utilizadas con fines diversos. El auge del género documental tanto en cine como en televisión pasa a menudo por un tipo de teatralidad comparable al de estos programas, aunque desarrolladas en direcciones distintas.

En el siglo XX cada vez más fenómenos artísticos y sociales se han construido sobre una conciencia explícita y abiertamente exhibida de sus estrategias de teatralidad. Esto contribuye a explicar que, en paralelo a la enorme atención que desde el Formalismo ruso ha habido por la cuestión de la literariedad, de manera más velada y difusa la pregunta acerca de la teatralidad ha funcionado de modo comparable a partir de los años sesenta. Se trata, no obstante, de acercamientos distintos que conviene diferenciar. Si el enfoque literario ha impuesto una imagen de la realidad, también de la realidad del propio teatro, y de la historia en tanto que texto, es decir, como una estructura fija que se ofrece para su interpretación (puesta en escena), la mirada teatral ha promovido una idea de la cultura como proceso antes que como resultado. La historia deja de entenderse únicamente como un conjunto de textos que nos llegan al presente y que se ofrecen quietos para su interpretación; junto a esto se ha ido afianzando un acercamiento dinámico a la historia y la realidad como un conjunto de actividades de puesta en escena, actuación física y percepción sensorial, de representaciones, ritos y ceremonias que articulan y dan sentido a nuestra realidad cotidiana, personal y pública. Una concepción teatral implica un mayor dinamismo y una dimensión operacional y física, procesual y performativa. La historia ya no se concibe como 


\section{LA TEATRALIDAD COMO CRÍTICA DE LA MODERNIDAD}

algo acabado, como un documento-monumento que esconde un significado único y verdadero que es necesario desvelar, sino como un proceso activo que vive en un continuo hacerse y que no puede entenderse más allá de sus situaciones concretas y pragmáticas de ocurrencia, en las que el espectador/lector va a pasar a ocupar un espacio central; y no podemos olvidar que el espectador último del espectáculo de la historia es aquel que se vuelve hacia el pasado desde su propio presente, es decir, el que está escribiendo esa historia. La mirada del que observa, del que se interroga y busca significados, esencial en el juego de la teatralidad, se proyecta también al plano de la hermenéutica, como nos recuerda entre otros Gadamer, para denunciar la falacia en que consiste todo juego de interpretación que trata de hacer transparente, neutral y gratuito el medio, el espacio y la situación desde la que se mira, el espacio del espectador.

La pregunta acerca de la teatralidad y el performance, formulada en ámbitos distintos y sin una relación previa entre ellos, vendría a sumarse al interrogante sobre la literariedad, no para excluirlo, sino para añadir otro enfoque al análisis de los mecanismos sociales y artísticos, de la construcción de la historia y las identidades. Estrechamente ligado a este enfoque se encuentra cl auge de los estudios sobre performance desde los años sesenta y setenta, la difusión de los conceptos de fiesta, rito y juego en la Etnografía y la Sociología modernas o el denominado giro pragmático en la Lingüística y la Filosofia durante el siglo XX (Ficbach 1996; Carlson 1996; Fischer-Lichte y Kolesch 1998; Schechner 2002; Cornago 2003). Detrás de estos acercamientos subyace la necesidad de pensar toda realidad como un proceso dinámico, un acto de puesta en escena que solo funciona en la medida en que se está produciendo, es decir, que está siendo percibido en tiempo real por el que lo vive.

Curiosamente, no ha sido en el ámbito de los estudios teatrales donde primero se ha desarrollado esta aproximación, sino en los campos de la Lingüística, la Antropología y la Sociología ya desde los años cincuenta y sesenta (Austin 1962; Goffman 1959; Turner 1969; Burns 1973). Es solo a partir de los ochenta cuando en departamentos de teatro de distintas universidades se ha adoptado este enfoque, que partiendo de lo escénico llega a campos tan distintos, lo que le ha dado una nueva actualidad a los estudios teatrales. En el ámbito germano, una de las culturas con mayor especialización en este terreno, esta área de estudios recibe el nombre de Theaterwissenschaft; solo en Berlín, por ejemplo, cabría destacar las investigaciones impulsadas durante los años noventa por Fiebach al frente del Departamento de Teatro de la Humboldt Universität o más recientemente de Fischer-Lichte en el de la Freie Universität. Como en su momento sucedió con los estudios literarios, el interés de los estudios teatrales en la actualidad pasa por su proyección a otros ámbitos de estudio no específicamente escénicos, y viceversa, por la reconsideración del hecho teatral -como también se hizo con el texto literario- desde esos otros campos.

Sin embargo, a pesar de estos avances y la cada vez más amplia utilización de este concepto, no poseemos un conocimiento claro y en profundidad de sus complejas implicaciones. Incluso dentro de los estudios teatrales, no es habitual encontrar una discusión explícita de las estrategias de teatralidad empleadas en una determinada obra, autor o período cultural. Todavía estamos lejos de entender la producción de un creador escénico o cinematográfico, plástico o literario, así como de un determinado período histórico en su conjunto, desde el punto de vista de sus estrategias de teatralidad. Frente a este enfoque minoritario, la idea del teatro -y paralelamente también de la historia-como un texto, ya sea texto dramático o espectacular -el tratamiento metodológico es comparable-, que se ofrece para la interpretación, sigue siendo lo dominante.

Preguntarnos por la literariedad o por la teatralidad de una obra, incluso de una obra no escénica, como una novela, un cuadro, una película o una instalación plástica, implica dos acercamientos diversos, que conllevan a su vez aparatos teóricos y herramientas de análisis distintas. En el ámbito de la representación y especialmente de cara a su dimensión teatral, tan importante es el personaje, la historia y el sentido de la trama como los actores, la concreción física del escenario o el espacio que ocupa el espectador, es decir, la situación y modo de su puesta en escena y comunicación. Si bien, hemos de insistir en que no se trata de acercamientos excluyentes, sino al contrario, capaces 


\section{ÓSCAR CORNAGO}

de arrojar miradas complementarias sobre una determinada obra artística o fenómeno cultural. Y lo mismo podríamos hacer extensible a la comprensión de la historia, ya sea en cuanto texto al que interrogamos acerca de sus posibles sentidos, tramas y personajes, o como una realidad que acontece, se pone en escena, se representa frente a un público con unos intereses y medios determinados; la pregunta en este último caso ya no sería por el sentido de la historia (o del arte), sino por sus modos de funcionamiento, comunicación y pecepción.

El elemento inicial para empezar a entender la teatralidad es la mirada del otro; éste es su desencadenante. Todo fenómeno de teatralidad, social o artística, se construye a partir de un tercero que está mirando. Sc trata de un acercamiento muy diferente al de la literariedad, pues un texto, ya sea en su sentido estricto como texto escrito, o en sentido figurado, como texto escénico, cinematográfico o cultural, existe al margen de quien lo mira. Es una realidad sostenida por una determinada estructura que cohesiona sus clementos y que no necesita ser mirada/leída por alguien para existir, sí quizá para ser interpretada, pero su existencia material es previa al momento de la interpretación. Es cierto que todo fenómeno estético, y por tanto cualquier obra artística, está construida pensando en el efecto que ha de causar en su receptor, pero el caso de la teatralidad no solo se piensa en función de su efecto en el otro, sino que no existe como una realidad fuera del momento en el que alguien la está percibiendo; cuando éste deje de mirar, de oírla o sentirla, dejará de haber teatralidad. En el campo de lo teatral nada existe fuera de su proceso inmediato de recepción sensorial, y esto es algo que todavía está por asimilar en las historias teatrales, a pesar del interés en las últimas décadas por el hecho de la puesta en escena, un interés que a menudo se ha traducido en un mero apéndice documental sin mayores repercusiones para el texto dramático, es decir, que no ha generado un espacio de conflicto desde el que entender con nuevos ojos la cualidad de la palabra (dramática) en convivencia con cl cuerpo y la acción, el espacio y el tiempo de la (re)presentación.

El protagonismo del espectador nos ofrece la segunda clave del hecho teatral: se trata de algo procesual, que solo tiene realidad mientras está funcionando. No es posible pensarlo como un producto acabado o como un texto que espera paciente la llegada de un lector/receptor para ser interpretado. Pongamos un ejemplo paradigmático de algo teatral en cualquier cultura, como el hecho de disfrazarse. Nadie se disfraza si no va a ser visto por otra persona; uno se disfraza para exhibirse luego en un espacio público, donde la mirada del otro va a desencadenar el mecanismo de la teatralidad. Si un disfraz no exige la mirada del otro, ya no estaría concebido como un disfraz, sino como un vestido específico para una determinada circunstancia. Pensemos, por ejemplo, en el atuendo de un sacerdote cuando celebra una misa o de un profesional para desarrollar su trabajo, como la bata de un médico, en ambos casos el vestido tiene una función, ya sea de orden trascendental o práctico. En el caso del disfraz no hay ninguna otra función que el ser visto por otro. Ahora bien, entre estos dos casos propuestos, el del cura es más teatral que el del médico, porque si bien cada elemento de la ceremonia se justifica por su significado trascendental, el acto en sí de la ceremonia participa de la teatralidad en mayor medida que la labor del médico, justificada de manera intrínseca; de ahí la importancia en el primer caso de la presencia del feligrés que acude a la misa y sin la cual el sentido del acto ritual sería dudoso.

El tercer elemento constituyente de la teatralidad es el fenómeno de la representación, es decir, la dinámica de engaño o fingimiento que se va a poner en juego: el actor oculto tras su personaje o el personaje manipulado por el actor. Volviendo con el ejemplo del disfraz, pensemos en un caso concreto cuya indudable fuerza teatral le ha conferido un tratamiento cultural específico: $\mathrm{cl}$ travestismo sexual, es decir, un hombre o una mujer se disfrazan para aparentar el sexo contrario. Retomando los elementos anteriores, acordaremos que nuevamente la mirada del otro es el punto de partida desde el que se construye la teatralidad. Un hombre se disfraza de mujer, para ello tendrá que tener en cuenta el efecto que va a producir cada uno de los clementos de su atuendo en aquel que está mirando; dependiendo en qué cultura estemos, los clementos utilizados scrán diferentes. Pero, como dijimos antes, no se trata únicamente de disfrazarse, sino que hay que 


\section{LA TEATRALIDAD COMO CRÍTICA DE LA MODERNIDAD}

salir al espacio público para que esta dinámica de fingimiento comience a funcionar, de manera que todo el disfraz cobre sentido al realizarse finalmente en el acto inmediato de su percepción. El hombre no se viste de mujer para estar solo en casa; en ese caso sería objeto de su propia mirada en un juego de desdoblamiento de la personalidad: alguien que se mira a sí mismo. Pero generalmente es cuando el travestido o la travestida está frente a los demás que se despliega el mecanismo de la teatralidad.

En resumen, podemos definir la teatralidad como la cualidad que una mirada otorga a una persona -como caso excepcional se podría aplicar a un objeto-que se exhibe consciente de ser mirado mientras está teniendo lugar un juego de engaño o fingimiento. Veamos ahora cómo funciona este mecanismo.

Lo fundamental en el efecto de la teatralidad es que esta dinámica de engaño o fingimiento se haga visible, es decir, que el que mira descubra por detrás del disfraz de mujer la verdadera identidad de hombre. Si cl disfraz estuviera tan bien realizado que el que mira no descubriese el engaño, la representación dejaría de ser teatral. El engaño se haría invisible y el juego teatral no tendría lugar, pero sí la representación; es por esto que la teatralidad supone un modo consciente de la representación. Ésta es la diferencia esencial entre teatralidad y representación, términos que a menudo se confunden, incluso por la crítica especializada, que tiende a sustituir cl segundo por el primero, de modo que ya no se habla de representaciones, sino de teatralidades: teatralidades sociales, teatralidades políticas, teatralidades religiosas o teatralidades escénicas. La representación constituye un estado, mientras que la teatralidad es una cualidad gradual que adquieren algunas representaciones y que se puede dar en mayor o menor medida, a diferencia de la representación, que no admite gradación, es decir, no se representa más o menos, se presenta o no se representa; sin embargo, una representación sí puede ser más o menos teatral, incluso la misma representación puede ser percibida en un momento como no teatral y más tarde como teatral, como falsa, porque algo haya cambiado en el modo de percepción. El fenómeno de la teatralidad resulta más dependiente de una pragmática cultural concreta y una situación real de comunicación que define su funcionamiento y fuera de la cual no podría entenderse. Si las representaciones se construyen a menudo con la ambición de dejar una huella para la posteridad, el signo de un poder, la teatralidad, como mecanismo, se agota en el presente de su comunicación. Empleando la filosofía deleuziana, diríamos que tiene una vocación menor, que desestabiliza por un instante el jucgo de la representación, aunque no deje de apoyarse en él. También el poder ha recurrido con frecuencia a cstrategias de teatralidad, pero no con la intención de que éstas desvelen cl engaño de la representación, sino al contrario, para que lo potencien; por eso la misma representación puede esconder para un determinado público, que cree en lo que está viendo, su teatralidad y para otro revelarse en todo su artificio, construido desde unos determinados intereses, de ahí que la cita inicial de Lyotard que abre este ensayo comience recordando que lo teatral nos sitúa en el centro de un vacío y de una ausencia, de un descreimiento, del nihilismo. Éstas son las potencias de lo falso, que se pueden dirigir en uno u otro sentido.

La teatralidad se construye en un continuo atravesar la representación, fugaz y en movimiento, para iluminarnos los mecanismos sobre los que ésta se construye. Supone una mirada oblicua sobre la representación, de tal manera que hace visible su funcionamiento. Tiene lugar, por tanto, un efecto de redoblamiento de la representación, una especie de representación de la representación; esto es, el travestido no representa el ser-mujer, éste sería un estadio de representación que se encuentra de manera habitual en las mujeres. Los tacones, el vestido, el maquillaje o la peluca se convierten en signos del ser-mujer. En este caso, estos signos se exageran de modo que se haga visible el juego; no se trata, por tanto, de representar lo femenino, sino de representar que se representa el ser-mujer. Asistimos a una presentación de la representación o una puesta en escena de esta última, que saca a la luz los procedimientos que de otro modo pasarían inadvertidos. De esta suerte, la teatralidad proyecta un tipo de mirada específica sobre el hecho de la representación. Ésta se hace más consciente, y el espectador disfruta al ver de forma consciente el procedimiento 


\section{ÓSCAR CORNAGO}

de la representación, el juego del artificio y el desequilibro de las identidades, el soy uno, pero represento otro, soy yo pero en realidad no lo soy. Desde este cnfoque, la teatralización de la vida social y el arte en el mundo contemporáneo tiene mucho que ver con el modo consciente que ha adquirido la representación en la Modernidad y el juego constante con las distancias entre lo que se es y lo que se representa.

Lo fundamental en la dinámica de la teatralidad es este sistema de tensiones generado por la distancia de teatralidad, que se abre entre lo que uno ve, por un lado, y lo que uno percibe como escondido detrás de lo que está viendo, por otro. Se delimitan así dos campos: el campo de lo que se ve, de lo que se representa, de lo que es visible y está desplegado en la superficie, y el campo de lo que queda oculto, de lo que no se ve, pero se intuye o se deja adivinar. Entre ambas regiones se establece la distancia de teatralidad, que articula el vacío entre estos dos campos. En este espacio se juega la teatralidad, producida por un sistema de tensiones entre una región y la otra, y este espacio solo puede ser construido - descubierto- por la mirada del otro; es un espacio, por tanto, inestable, vivo y en movimiento, que únicamente se construye como resultado de un proceso activo. Utilizando el concepto desarrollado por Turner $(1969,1982)$ para el análisis de los ritos, diríamos que es un espacio liminal -de transición- entre un estadio y otro, un espacio móvil entre lo que soy y lo que parezco, entre lo que muestro y lo que oculto; pero de modo que nunca deja de ser uno y otro al mismo tiempo.

El mecanismo semiótico de la representación se desarrolla en el espacio de lo visible, ahí se sitúan los significantes y los significados. Conviene no confundir el espacio oculto con el espacio significante, por una parte, y el espacio de superficie con el de los significados, por otra; es decir, cl hombre no es el significante del ser-mujer, sino que los signos de la feminidad están construidos todos cllos en el espacio del ser-mujer, de la superficie de lo visible, y es este ejercicio de construcción mediante cl vestido, el maquillaje, el peinado, etcétera, el que se acentúa para potenciar la teatralidad. La distancia abierta entre ese ser-hombre (que aparentemente se oculta) hasta el ser-mujer (que se muestra) es la que permite iluminar el proceso de representación que está teniendo lugar. De este modo, la teatralidad saca la representación a la superficie, pero la verdad de esta representación no coincide con la verdad de la teatralidad. La verdad semiótica de la primera representación (el ser-mujer) queda desvelada como un engaño al lado de la verdad performativa de la teatralidad. Su verdad es su ser-como-juego, fingimiento y disimulo, y su realidad no es la realidad de lo representado, sino la realidad del proceso de representación que está teniendo lugar. Las profundidades del proceso semiótico se despliegan sobre la superficie, es como un calcetín al que se le da la vuelta -siguiendo la definición que ofrece Richard Foreman de su teatro (en Reynaud 1981: 11)-, ahora vemos con claridad cómo se construye la semiosis del ser-mujer, pero por detrás de esta representación convertida en espectáculo queda un vacío que distancia la representación, la denuncia como tal y nos la hace ver como algo casi siniestro, arrojando sobre su pretendida verdad un extraño interrogante. La clave de la teatralidad no es llegar a saber de quién se trata verdaderamente, si de un hombre o una mujer, si de un actor o un personaje -esta sería más bien la finalidad de la representación, poner en claro el juego de sustituciones-, sino el campo de tensiones que se establece entre ambos.

Repasando algunas de las líneas más innovadoras del teatro durante el siglo XX, comprobamos que en muchos casos podemos explicar su evolución por esta búsqueda de una realidad específicamente escénica, es decir, teatral; su verdad ya no radica en la verosimilitud de lo que se está representando, sino en la verdad del juego que se lleva a cabo. Desde la convención consciente de Meyerhold hasta el Teatro Cero de Kantor o la estilizada geometría de Robert Wilson, la escena moderna ha crecido haciendo visible sus estrategias de teatralidad, aunque éstas han llegado a adquirir tal grado de complejidad que más que arrojar una luz sobre la representación la envuelven sobre un interrogante. La realidad última de estos mundos radica precisamente en lo real de ese juego que se está desarrollando en escena. Desde una poética distinta y con mayor transparencia, por poner otro cjemplo, el teatro de Els Joglars ha avanzado igualmente por esta línea de construcción 


\section{LA TEATRALIDAD COMO CRÍTICA DE LA MODERNIDAD}

de un juego escénico explícito, que no sólo es consciente de sus propiedades teatrales sino que las expone abiertamente, haciendo ostentación material y física, como corresponde a todo lo teatral, de las trazas características de su mundo de bufones (Cornago 2004a). Bien es cierto que hay otros modelos teatrales que han continuado desarrollando una poética escénica realista heredada del siglo XIX y puesta al día a través del cine y sobre todo, ya desde los años sesenta, de la televisión, perdiendo de vista que los efectos de realidad a los que llegó primero el cine y más tarde la televisión no pueden ser transpuestos de forma directa a la escena, que carece de la mediación de las cámaras e impone sobre el espectador un modo de recepción diferente al que tiene lugar cuando éste se sitúa, no frente a un cuerpo real, sino frente a una imagen proyectada en una pantalla.

Las dos prácticas artísticas que quedan más cerca del teatro y por tanto del hecho explícito de la teatralidad son, por un lado, el cine, el vídeo y la televisión, que comparten con el teatro la interpretación actoral, $y$, por otro, la escritura dramática -a la que se podrían sumar los guiones de cine y televisión-, que nos sitúa ya en una esfera específicamente literaria, pero de una literatura pensada todavía para su realización escénica. Estos dos caminos apuntan distintas vías para seguir pensando el fenómeno de la teatralidad dentro del paisaje artístico de cada momento, pero igualmente podríamos mirar las artes plásticas, la fotografía o la música sub species theatralis, e interrogarnos acerca de sus estrategias de puesta en escena, corporalidad, comunicación sensorial y medialidad, que son los cuatro pilares que Fischer-Lichte (2000, 2001 a, 200 l b, 2003) distingue dentro del fenómeno de la teatralidad - a cada uno de los cuales le dedicó un volumen como resultado de su proyecto de investigación sobre el concepto de teatralidad-.

En relación al cine habría que destacar aquellos momentos y creadores específicos que han acentuado los rasgos de teatralidad inherentes al rodaje de una película, aunque en cada caso esto se haya hecho por razones diversas; pensemos en los comienzos del cinematógrafo, en las vanguardias rusas o en la Nouvelle Vague. Tanto para el cine como para otras artes, como nos recuerda Romero Esteo (2000) -sin duda quien más lejos ha llevado la teatralización de la escritura dramática-, los períodos de vanguardia han supuesto la teatralización de todas las artes y en general-podemos añadir-de la vida social. Esto ha hecho que las primeras décadas del siglo $\mathrm{XX}$ y, posteriormente, los años sesenta y setenta hayan sido algunos de los momentos en los que se aprecia con más claridad esta teatralización de los lenguajes artísticos. Ahora bien, a partir de los setenta, las premisas estéticas de las vanguardias, la consideración del arte como búsqueda y experimentación, se han ido asimilando en sectores más amplios, lo cual explica que no sea difícil encontrar desde entonces hasta nuestros días ejemplos de escrituras y actuaciones, en el sentido más amplio de estos términos, que han subrayado su ser como puesta en escena, representación, construcción y performance.

Resulta significativo que esta teatralización a menudo haya sido el efecto de una realización consciente de la propia escritura. Esto ha conducido a una suerte de negación del propio campo artístico a través del acercamiento a sus límites, buscando la confrontación con otros medios. Desde estos bordes exteriores se consigue hacer visible un determinado sistema como un mecanismo autónomo puesto en escena, lo que ha sido característico de los momentos de mayor innovación, también para la literatura del siglo XX cuando ha buscado asimilarse a la imagen plástica, cl dibujo o la música (Monegal 1998; Blesa 1998). La teatralización de las artes ha supuesto un camino de autorreflexión de cada medio sobre sí mismo, para lo que ha sido necesario su levantamiento como un sistema autónomo. De este modo, las modernas instalaciones pueden entenderse como una puesta en escena de las artes plásticas o la música, y el vídeo ha proporcionado un instrumento de reflexión sobre el cine y la construcción de las imágenes. Retomando el análisis de Gadamer (1960: 154) sobre el juego, podemos afirmar que en este énfasis en la teatralidad de las imágenes, de la escritura o los sonidos, el arte, metáfora de la realidad, se juega a sí mismo adquiriendo una suerte de autoconciencia:

Sólo en este giro gana el juego su idealidad, de forma que pueda ser pensado y entendido como él mismo. Sólo aquí se nos muestra separado del hacer representativo de los jugadores y consistiendo en la 


\section{ÓSCAR CORNAGO}

pura manifestación de lo que ellos juegan. Como tal, el juego, incluso con lo imprevisto de la improvisación, se hace en principio repetible, $y$ por lo tanto permanente.

A lo largo de la Modernidad la teatralización de las artes ha servido como una forma de resistencia frente a modelos de representación dominantes, desde la escritura de Mallarmé o Gertrude Stein a la puesta en escena de la voz narrativa en Juan Goytisolo o Julián Ríos; desde el constructivismo ruso en cine y artes plásticas hasta la obra de Peter Greenaway y Lars von Trier, por citar ejemplos distantes que muestran sin embargo una voluntad comparable de entender la creación y la historia como construcción, mecanismo y actuación, aunque sea de la propia escritura sobre el papel. Este punto de partida común, aunque adquiera desarrollos tan distintos en función de poéticas y momentos culturales diversos, apunta a una concepción paralela del arte como juego y representación, puestos en marcha y hechos visibles por esta voluntad performativa y teatral a la vez (Cornago 2005), reflejo de un tiempo histórico que ha llevado hasta el extremo el deseo de realizarse a través de la puesta en escena de sus discursos ideológicos. El fracaso de las representaciones históricas, unido al exceso de las ficciones y la inflación de la palabra, justifica en última instancia el desarrollo de la teatralidad como modo de resistencia frente a un poder que se levanta sobre las ruinas de las representaciones dialécticas:

La dialéctica averiada fue: el proletariado alemán adhiriéndose al hitlerismo; el proletariado ruso adhiriente a Stalin; ambos masacrándose; el proletariado español aplastado por la aviación fascista, rematado en Barcelona por los estalinianos; el proletariado francés abandonando las posiciones ocupadas en el 36, rematado por los reformistas; el proletariado chino aniquilado por Chang y la política de Stalin (Lyotard 1973: 121).

Uno de los modos fundamentales para potenciar la teatralidad, ya sea de la escritura, de la representación o la actuación, es el énfasis en la exterioridad material, la ostentación de la superficie de representación, de los signos que se van a poner en juego. $A$ través de un exceso de materialidad, el código llama la atención sobre sí mismo, haciéndose más visible. Este exceso de materialidad está relacionado con la necesidad de atraer la mirada del otro, requisito para que todo se ponga en funcionamiento. La representación enfatiza su envoltorio exterior para seducir al otro con sus formas; pero detrás de este exceso sensorial se descubre un vacío, que siguiendo la dialéctica negativa de Adorno nos defiende contra la realización final de la representación y su juego de poder: esa aparente mujer en realidad no es una mujer, sino que es un hombre; y entre uno y otro se juega esa distancia desestabilizadora, que produce una especie de vértigo en el que mira, un efecto de desplazamiento de los signos que abre una fractura entre ellos. Este vacío funciona también como motor de atracción tras las apariencias de superficie. Estas imponen su materialidad, cercana, inmediata y performativa, emancipadas de cualquier otra finalidad que no sea su capacidad de atracción, sostenidas por ese vacío que ocultan. En la escena todo debe seducir y «en el movimiento de la seducción - como explica Baudrillard (1990: 54)- es como si lo falso resplandeciera con toda la fucrza de la verdad». Esto nos invita a ir más allá, nos intriga acerca del secreto que guardan las caretas; pero cuando uno se acerca lo que descubre es el límite donde empieza un vacío, donde los sentidos se desequilibran, mientras que la tentación de seguir avanzando se hace más intensa:

Ese Otro no es el lugar del deseo o la alienación, sino del vértigo, del eclipse, de la aparición y la desaparición, del centelleo del ser, si puede decirse (pero no hay que decirlo). Pues la regla de la seducción es precisamente el secreto, $\mathrm{y}$ cl secreto es el de la regla fundamental (185).

En todos los órdenes culturales, afirmar de algo que es teatral implica una mirada consciente que hace visible los códigos exteriores que están siendo empleados. La realidad queda desvelada como un juego de representaciones y la veracidad de su sentido ulterior pasa a ser cuestionada. Pongamos por ejemplo que una persona está en un restaurante y mira fijamente a una pareja sentada en la mesa del lado. De pronto tiene la sensación de que esa situación es muy teatral, que ya la 


\section{LA TEATRALIDAD COMO CRÍTICA DE LA MODERNIDAD}

conoce, que los códigos le son familiares. Esto se produce porque su mirada es capaz de detectar tras los gestos, movimientos y entonaciones que le llegan de esa pareja, un determinado código con el que se construye un sentido determinado, como el atuendo y el maquillaje del travestido construyen la feminidad; pero sabemos que detrás de ese acto de representación redoblada sobre sí mismo, hay un límite, detrás del cual se esconde un vacío, que se adivina, pero no se significa, y que tratamos de cubrir desplegando en superficie esa representación. Una de las operaciones características de esta mirada teatralizante, como del que mira a esa pareja, es la delimitación de un espacio y un tiempo precisos, cl espacio y el tiempo de la actuación, en los que tiene lugar esa acción, descubierta como puesta en escena, como una realidad que sigue un guión previo. Esta dimensión escénica es la que da unidad a la representación, desgajándola del resto de la realidad, como si ese trozo de realidad pasara a estar entre paréntesis por tratarse de otro tipo de realidad, menos real y verdadera, más engañosa, porque juega a ser una cosa y la otra al mismo tiempo, lo que muestra y lo que oculta.

Combinando estos elementos, diríamos que la teatralidad potencia la exterioridad material de una situación dada en un espacio y un tiempo determinados. Esta operación tiene un efecto de vaciado de esos signos que se han subrayado. Al extraerlos de su contexto real, los signos quedan liberados de su significado contingente y dispuestos a su utilización en un plano simbólico. Por este motivo, más allá de aquel espesor de signos al que se refirió inicialmente Barthes -una definición de teatralidad que vía el diccionario de Patrice Pavis llegó hasta el último rincón del ámbito académico-, el teórico francés continúa su pensamiento sobre la teatralidad refiriéndose a ésta como una operación última necesaria para fundar un nuevo lenguaje: «Il faut en effet pour fonder jusqu 'au bout une langue nouvelle, une quatrième opération, qui est de théâtraliser. Qu'est-ce que tréâtraliser? Ce n'est pas décorer la représentation, c'est illimiter le langage» (Barthes 1971: 10). Esta operación está en la base de cualquier lenguaje artístico, que por medio de su materialidad exterior se proyecta hacia un plano simbólico en el que adquiere una pluralidad de significados. Es por esto que una obra de arte se ofrece a una diversidad de interpretaciones, porque los signos sobre los que se construye, extraídos de contextos reales, son proyectados en función de su materialidad específica hacia un plano poético. La teatralidad está, por tanto, en la base de cualquier operación artística, aunque no en todos los casos este mecanismo se lleve a cabo de modo explícito. En este sentido, la palabra poética, volviendo sobre la teatralidad de lo literario, puede ser definida como una palabra esencialmente teatral, que nos seduce con su materialidad exterior, que se pone en escena sobre el papel, haciendo ostentación de sí misma para significar algo que no es. Su verdad, como la del actor, no estaría en todo caso en lo que representa o sugiere, sino en su juego de representación, en su mecanismo simbólico.

A lo largo de los siglos XIX y XX la creciente conciencia de la realidad y la historia como un acto de representación ha hecho que la teatralidad pueda ser entendida como una suerte de paradigma de la Modernidad. En la época contemporánea, como explica Foucault en Las palabras y las cosas, se fragmenta la ciencia universal del orden y las medidas, la mathesis universales, que organizaba toda la realidad en función de un único sistema de representación. Su disgregación da lugar a numerosos sistemas de representación que replegados sobre sí mismo se hacen visibles desde sus límites exteriores, así como paralelamente la razón analizada por Kant se revela como un mecanismo emancipado en base a su funcionamiento específico. De este modo, las ciencias clásicas, como la Anatomía, la Gramática o $\mathrm{cl}$ análisis de las riquezas, que funcionaban a modo de interminables listados, se convierten en la Biología, la Filología y las Ciencias Económicas, sistemas de representación cerrados sobre sí mismos y apoyados en un funcionamiento específico, como los distintos sistemas estéticos. La mayoría de edad de la razón decretada por Kant va de la mano de su puesta en escena como sistema autónomo y de esa ambición de la historia por cumplirse como realización de sus propios discursos, de sus propias representaciones ideales, cuyo sostenimiento se hizo especialmente difícil a partir de los conflictos bélicos de alcance mundial que asolaron la cuna de la razón ilustrada y el compromiso político, como constataba Lyotard. 


\section{ÓSCAR CORNAGO}

Pero lo fundamental es que el centro de estos sistemas, lo que sostiene el ser de sus representaciones, deja de estar incluido en ellos mismos: la vida, el lenguaje o el valor de cambio pasan a ser el afuera, lo impensado. El origen que da lugar a estos campos de conocimiento supera el contenido mismo de la Biología, la Filología o las Ciencias Económicas; queda fuera de sus horizontes de representación, aunque los constituye desde ese afuera que solo conocemos por los propios límites del conocimiento, o en palabras de Foucault (1966: 217):

El hombre no se pudo dibujar a sí mismo como una configuración en la episteme, sin que el pensamiento descubriera, al mismo tiempo, a la vez en sí y fuera de sí, en sus márgenes, pero también entrecruzados con su propia trama, una parte de noche, un espesor aparentemente inerte en el que está comprometido, un impensado contenido en él de un cabo a otro, pero en el cual se encuentra también preso.

De esta suerte, estos sistemas hacen visibles sus modos de funcionamiento a través de las funciones biológicas, del funcionamiento del dinero o las flexiones gramaticales, pero no su ser; el principio de la representación escapa a esta, situándose en los espacios intersticiales, entre los diversos sistemas de representación; de ahí la necesidad de esas nuevas disciplinas agrupadas bajo la denominación de Ciencias Humanas, como la Sicología, la Antropología, la Sociología o la Teoría del Lenguaje, que han caracterizado la Modernidad y que tienen como objetivo el estudio de esos fenómenos que se hacen visibles en la base de estos sistemas de representación, como la vida, el hombre o el lenguaje, pero que al mismo tiempo quedan siempre más allá de estos.

La perspectiva de la teatralidad no sólo saca a la luz la exterioridad material de los sistemas de representación, sino también sus mecanismos de funcionamiento, dejando ver sus límites exteriores. Éstos se presentan, por tanto, como sistemas autónomos, emancipados de cualquier finalidad exterior a ellos mismos, lo que no quiere decir que dejen de convivir con otros sistemas y de reaccionar unos frente a otros. De manera comparable se podrían entender cada uno de los lenguajes estéticos tratando de llegar a ser lo que no son: la poesía que se quiere imagen o música, la música que quicre ser teatro, y la pintura poesía o el cine un cuadro detenido. Cada uno tiende a lo otro, como el hombre aparentaba ser mujer en el ejemplo anterior, para en el acto de su negación como unidad, hacerse más visible en tanto que juego y representación, siendo uno y lo otro al mismo tiempo, como también quiso Artaud.

Bajo el paradigma de la teatralidad y una concepción de la realidad como representación se despliega la cultura moderna. Esto implica un modo de entender el mundo a partir de sus limitaciones, desde la conciencia explícita del vacío que subyace a cada sistema de representación. En esta tensión entre un exceso de presencia que juega a seducirnos, atrayendo nuestra atención, y un defecto de presencia representada como ausencia, se establece una fisura que atraviesa la Modernidad, un abismo entre dos orillas incapaces de volver a unirse en una reconciliatoria identificación, una diferencia irresoluble. Sobre esa fractura abierta por las distancias de teatralidad y los campos de inestabilidades gencrados por éstas crece el pensamiento contemporáneo.

Siguiendo el mito bíblico, con el pecado original llega el castigo por el deseo de conocimiento y el ojo divino inaugura la historia de la representación (Enaudeau 1998): el hombre se siente desnudo bajo la mirada de Dios, se siente mirado, en mitad de un mundo entendido como escenario. La diferencia con la imagen del topos clásico del theatrum mundi consiste en que ya no se trata de representaciones concebidas desde sus resultados exteriores, sino desde sus procesos inmediatos de funcionamiento, desde sus juegos de inestabilidades, límites y vacíos. Ya no es una acción detenida como en un cuadro que simula una escena representada, sino un mecanismo que produce representaciones y en el que lo fundamental no es únicamente el resultado de esas representaciones, sino el mecanismo en sí mismo, que crece desde sus propios límites. Nacer para la representación supone, de este modo, abrir los ojos para descubrirse desnudo, verse como objeto y sujeto al mismo tiempo, delimitar la escena construida por el ojo del otro, para ser consciente de la finitud de uno y lo ilimitado del deseo. Se trata, finalmente, de una reflexión epistemológica acerca de los medios -de representación y conocimiento-sobre los que se construye la realidad. 


\section{LA TEATRALIDAD COMO CRÍTICA DE LA MODERNIIDAD}

La pregunta ante una representación, es decir, ante una obra artística o un determinado fenómeno social ya no es, por tanto, el qué significa, sino el cómo funciona. Y lo importante no es dar verosimilitud al resultado final, hacer pasar por cierto la verdad semiótica de la representación, porque sabemos desde el comienzo que inevitablemente va a tener siempre algo de falso, como toda representación teatral/social, sino en hacer creíble el proceso, el mecanismo de tensiones entre lo que se ve y lo que se oculta, porque en ese campo de inestabilidades se juega ahora la verdad de lo real. Este enfoque performativo se ha visto potenciado al extremo con la Modernidad. Sobre esta fractura de lo mismo, del pensamiento representacional y la lógica de la identificación de las realidades con los conceptos, de las superficies con las esencias, de las copias con los originales, crece una cultura de los medios, definidos paradójicamente desde sus comportamientos extremos. En detrimento de los referentes a los que éstos apuntan, los medios han proliferado hasta emanciparse de sus finalidades de representación, en función de sus funcionamientos emancipados. Desde un enfoque comparable, a raíz de la obra de Proust, Deleuze (1964:152) se refiere a la obra de arte - a lo que podríamos sumar la realidad social-como un mecanismo, un tipo de artefacto que no significa, sino que funciona, un "antilogos" asimilado a una «máquina y maquinaria cuyo sentido (todo lo que usted quiera) depende únicamente del funcionamiento, y el funcionamiento de las piezas separadas». Así pues, y en contra de la metodología interpretativa, concluía el teórico del Posestructuralismo: «La obra moderna no tiene problema de sentido, solo tiene problema de uso» (152).

La teatralidad es una maquinaria que hace visible unas cosas y oculta otras, pero lo importante no es la imagen final producto de la representación, sino el funcionamiento del mecanismo. En su funcionamiento radica el sentido de la realidad (representada); de ahí que Lyotard (1973: 60) insista en que «el problema central no es [...] la disposición representativa ni la cuestión, a ella ligada, de saber qué representar y cómo, definir una buena o verdadera representación; sino la exclusión o la forclusión de todo lo que se considera irreprescntable porque no recurrente», es decir, de todo lo que queda excluido como no representable - de lo que sale en televisión, sería la traducción en términos mediáticos-, pero que al mismo tiempo determina los límites de lo que se puede representar, es decir, de lo que se puede conocer y saber; y por eso el filósofo francés termina concluyendo que «la escenificación, técnica de exclusiones y de desapariciones, que es actividad política por excelencia, y ésta, que es por excelencia escenificación, son la religión de la irreligión moderna, lo eclesiástico de la laicidad» (Lyotard 1973: 60).

La Modernidad es también la crítica de la Modernidad; nace ligada a su crítica, como la mayoría de edad de la razón surge de la crítica kantiana de la razón. Y entre los elementos que van a ser objeto de ese ejercicio crítico sobre el que se construye la cultura contemporánea se sitúa la propia representación. Adorno (1966: 11) afirma que «desde que la filosofía faltó a su promesa de ser idéntica con la realidad o estar inmediatamente en vísperas de su producción, se encuentra obligada a criticarse sin consideraciones»; lo mismo podría afirmarse de la representación. Desde el momento en que ésta faltó a su promesa de ser idéntica a la realidad, la representación no puede aceptarse sin su crítica; y de ahí el protagonismo de la teatralidad, justificado por esa necesidad de convivir con la representación, pero al mismo tiempo con su crítica: representar algo, pero a la vez. hacer visible los mecanismos sobre los que se está construyendo esa representación. Esto explica también la cualidad barroca que recorre la Modernidad, un inquietante barroquismo que, como el sentido de la teatralidad que le es inherente, puede ser entendido igualmente como elemento orgánico y al mismo tiempo crítica de este tiempo (Van Reijen 1994; Cornago 2004b).

En la medida en que la teatralidad nos invita a un recorrido transversal por el espacio de la representación, una mirada que abre la representación a un tiempo inmediato, en alas de su propia materialidad exterior, supone también una crítica de la Modernidad. Lyotard (1988: 26) nos recuerda que «los siglos XIX y XX nos han proporcionado terror hasta el hartazgo», y añade: «Ya hemos pagado suficientemente la nostalgia del todo y de lo uno, de la reconciliación del concepto y de lo sensible, de la experiencia transparente y comunicable». La mirada teatral nos 


\section{ÓSCAR CORNAGO}

ofrece un puente hacia el otro lado de la representación, hacia su afuera, hacia el lugar del que nacen las representaciones: la presencia física, la acción y el juego desde donde se construyen, un puente hacia ese vacío que late tras lo que vemos, seducidos por su atractiva materialidad. La teatralidad supone un mecanismo que opera con los límites, con los límites entre lo que se muestra y lo que se oculta, entre lo que se finge y lo que se siente, entre lo que se representa y lo que se es, un juego, en suma, con los bordes de la representación, levantada ahora vía la teatralidad como un sistema autónomo, al igual que el poema sobre el blanco del papel en Marllarmé o el relato sobre sus propios mecanismos de narración en Larva, de Julián Ríos, o en El sitio de los sitios o Carajicomedia, de Juan Goytisolo, mecanismos de construcción que son a su vez estrategias de resistencia y destrucción, comparable al teatro o el cine que se producen como obras en tanto que resultados de unas reglas previamente fijadas que es necesario seguir hasta el final, así en Romero Esteo o Lars von Trier. La teatralidad hace aparecer la divergencia por debajo de la apariencia de unidad o totalidad, nos muestra la otra realidad que se esconde por detrás de la superficie de la representación-parece una mujer; pero es hombre-, y ahí suena la disonancia, porque «mientras la conciencia tenga que tender por su forma a la unidad, es decir, mientras mida lo que le es idéntico con su pretensión de totalidad, lo distinto tendrá que parecer divergente, disonante, negativo». (Adorno 1966: 14).

Las transformaciones experimentadas por el teatro del siglo XX, como espacio por excelencia de la representación, proporcionan un interesante botón de muestra de esta necesidad de disonancia que la teatralidad hace surgir en mitad de la representación, que es siempre la representación de un poder. Bernard Dort, espectador atento a las evoluciones de la escena occidental desde los años cincuenta, subrayó el hecho de que la teatralidad iba más allá de ese espesor de signos al que se refirió inicialmente Barthes: «Elle est aussi le déplacement de ces signes, leur impossible conjonction, leur confrontations sous le regard du spectateur de cette représentation émancipée» (Dort 1988: 183), en la que se ha convertido no solo la escritura poética, las artes plásticas o el cine, sino también, como cabía esperar, el propio teatro, y en términos generales los distintos mecanismos que regulan la vida social.

De cara a la Modernidad, la crítica de la teatralidad consiste en hacer visible este desencuentro entre lo que se representa y lo que se es, entre lo que vemos y lo que se esconde detrás, entre unos signos y otros, entre la palabra y los gestos, entre las apariencias y los sentidos. La teatralidad se levanta sobre ese exceso de materialidad que es en primer lugar el cuerpo, construido a partir de las presencias físicas de los actores teatrales o sociales, y ese exceso se erige finalmente en un signo de interrogación acerca del posible sentido de la representación. Si la presentación remite a esa atractiva materialidad, la representación queda huérfana de un sentido, al menos de un sentido único, dentro de ese baile de signos y distancias que articulan el arte y la socicdad moderna. «Dudar de la representación -como explica Lyotard (1973: 109)- es manifestar la relación teatral (en música, en pintura, en política, en teatro, en literatura, en cine) como regida por un dispositivo libidinal arbitrario». Ese vacío al que remite por último la representación se proyecta sobre cl lugar antes invisible del espectador, que queda así situado en el centro del escenario, confrontado con esa dificultad de tener que dar sentido a unas representaciones que se gozan en su juego autónomo; de ahí que Dort termine concluyendo que la vocación misma de esta escena teatral no sea la de representar un texto u organizar un espectáculo, «mais d'être une critique en acte de la signification. Le jeu y retrouve tout son pouvoir. Autant que constrution, la théâtralité est interrogation du sens» (184). Ésta es también la teátrica pagana a la que se refiere Lyotard, una teatralidad que dinamita el poder de la representación y la representación del poder, porque al cortar la relación de la apariencia de mujer con el ser mujer, «al suprimir la relación de signo y su excavamiento, es la relación de poder (la jerarquía) lo que se hace imposible, y por consiguiente la dominación del dramaturgo+escenógrafo+coreógrafo+decorador sobre los supuestos signos, así como también sobre los supuestos espectadores» (Lyotard 1973: 96). Frente a la proliferación desatada de representaciones, historias e imágenes en la que se ha convertido la Modernidad, la lección última del arte contemporáneo, de esta teatralidad crítica de la Modernidad, no es añadir 


\section{LA TEATRALIDAD COMO CRÍTICA DE LA MODERNIDAD}

una representación más, sino hacer una representación menos, como afirmó Deleuze (1979) del teatro de Carmelo Bene, sustraer las constantes sobre las que se construyen las representaciones y las Historias como signos de poder. Ésta es la vocación minoritaria de la teatralidad moderna, un mecanismo que opera por eliminación, que se construye sobre su inestabilidad, operativa, física e inmediata, el poder político de lo negativo, que diría Adorno, las potencias de lo falso, la traición de los simulacros como paradigma último de la teatralidad moderna:

El simulacro no es una copia degradada, oculta una potencia positiva que niega original, copia, modelo y reproducción. [...] Lejos de ser un nuevo fundamento, se traga todo fundamento, asegura un hundimiento universal, pero como acontecimiento positivo y gozoso, como de fundamento (Deleuze 1969: 328).

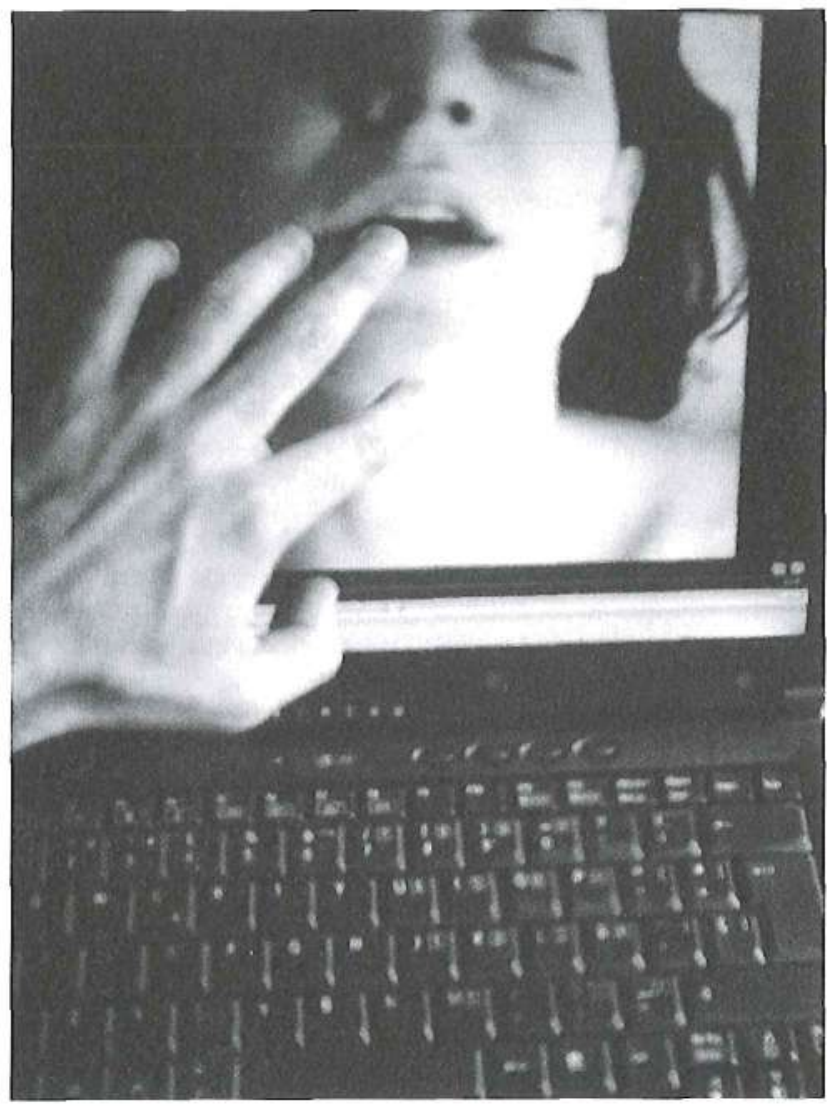




\section{ÓSCAR CORNAGO}

\section{REFERENCIAS BIBLIOGRÁFICAS}

ADORNO, Theodor Wiesengrund (1966): Dialéctica negativa, Madrid, Taurus/Cuadernos para el Diálogo, 1975.

AUSTIN, John Scarle (1962): How to Do Things with Words, Cambridge, Harvard University Press.

BARTHES, Roland (1971) : Sade, Fourier; Loyola, Paris, Éditions du Seuil.

BAUDRILLARD, Jean (1990): La transparencia del mal. Ensayo sobre los fenómenos extremos, Barcelona, Anagrama, 1991.

BLESA, Túa (1998): Logofagias, Los trazos del silencio, Zaragoza, Trópica.

BURNS, Elizabeth (1973): Theatricality: A Study of Convention in the Theatre and in Social Life, New York, Harper \& Row.

CARLSON, Marvin (1996): Performance: A Critical Introduction, London / New York, Routledge.

CORNAGO, Óscar (2003): Pensar la teatralidad. Miguel Romero Esteo y las estéticas de la Modernidad, Madrid, Fundamentos/RESAD.

(2004a): "Teatralidad y teatrería en la sociedad del espectáculo (las estrategias del Bufón)", en Teatro y sociedad en la España actual, eds. Wilfried Floeck y María Francisca Vilches de Frutos, Madrid/Frankfurt am Main, Iberoamericana/Vervuert, 2004, pp. 21-222.

- (2004b): "Nuevos enfoques sobre el Barroco y la (Pos)Modernidad (a propósito de dos estudios de Fernando R. de la Flor)", Dicenda. Cuadernos de Filología Hispánica (Universidad Complutense de Madrid) 22, pp. 27-51.

- (2005): Resistir en la era de los medios. Estrategias performativas en literatura, teatro, cine y televisión, Madrid/Frankfurt am Main, Iberoamericana/Vervuert.

DAVIS, Tracy C. y Thomas POSTLEWAIT (2003), "Theatricality: An Introduction", en Tracy C. Davis y Thomas Postlewait, eds., Theatricality, Cambridge, Cambridge UP, pp. 1-39.

DELEUZE, Gilles (1964): Proust y los signos, Barcclona, Anagrama, 1995.

— (1969): Lógica del sentido, Barcelona, Barral, 1971.

— (1979): “Un manifiesto menos”, en Carmelo Bene y Gilles Deleuze, Superposiciones, Buenos Aires, Ediciones del Sur, 2003, pp. 75-102.

DORT, Bernard (1988) : La représentation émancipée, Arles, Actes Sud.

DUBATTI, Jorge (2003): El convivio teatral. Teoría y práctica del teatro comparado, Buenos Aires, Atuel.

ENAUDEAU, Corinne (1998): La paradoja de la representación, Buenos Aires, Paidós, 1999.

EVREINOV, Nikolaj Nikolaevich (1908): El teatro en la vida, Buenos Aires, Leviatán, 1956.

FÉRAL, Josette (2003): Acerca de la teatralidad, Bucnos Aires, Nueva Generación/Universidad de Buenos Aires.

_ Jeannette LAILLOU SAVONA y Edward A. WALKER, eds. (1985) : Théâtralité, écriture et mise en scène, Québec, Éditions Hurtubise HMH.

FIEBACH, Joachim (1996): "Theatralitätsstudien unter kulturhistorisch-komparatistischen Aspekten”, en Joachim Fiebach y Wolfgang Mühl-Benninghaus, eds., Spektakel der Moderne. 


\section{LA TEATRALIDAD COMO CRÍTICA DE LA MODERNIDAD}

Bausteine zu einer Kulturgeschichte der Medien und des darstellenden Verhaltens, Berlin, Vistas, pp. 9-68.

— y Wolfgang MÜHL-BENNINGHAUS (1998) : Keine Hoffnung, keine Verzweiflung: Versuche um Theaterkunst und Theatralität, Berlin, Vistas.

FISCHER-LICHTE, Erika (1995a): "Theatricality: A Key Concept in Theatre and Cultural Studies", Theatre Research International 20. 2, pp. 85-89.

— (1995b): "From Theater to Theatricality - How to Construct Theatre", Theatre Research International 20.2, pp. 97-105.

— et al. (2000): Inszenierung von Authentizität, Tübingen, Francke.

— et al. (2001a): Wahrnehmung und Medialität, Tübingen, Francke.

— et al. (2001b): Korporalität, Tübingen, Francke.

_ et al. (2003): Performativität und Ereignis, Tübingen, Francke.

- y Dorisch KOLESCH, eds. (1998): Kulturen des Performtiven, Berlin, Akademic Verlag, 1998. (núm. monográfico de la revista Paragrama 7.1.)

FOUCAULT, Michel (1966): Las palabras y las cosas. Una arqueología de las ciencias humanas, Madrid, Siglo Veintinuo, 1968.

GADAMER, Hans-Georg (1960): "El juego como hilo conductor de la explicación ontológica", Verdad y método. Fundamentos de una hermenéutica filosófica. Salamanca, Ediciones Sígueme, 1977.

GOFFMAN, Erving (1959): The Presentation of Self in Everyday Life, Garden City, N. Y., Doubleday.

LYOTARD, Jean-François (1973): Dispositivos pulsionales, Madrid, Fundamentos, 1981.

- (1988): La Posmodernidad (explicada a los niños), Barcelona, Gedisa.

MONEGAL, Antonio (1998): En los límites de la diferencia. Poesía e imagen en las vanguardias hispánicas, Madrid, Tecnos.

REYNAUD, Bérénice (1981): "Petite introduction à l'oeuvre de Richard Foreman", Théâtre Public, hors série 1, pp. 8-23.

ROMERO ESTEO, Miguel (2000): "Mi personal visión Post-Vanguardia del Teatro", Aula de Teatro. Cuadernos de Estudios Teatrales, 15, pp. 7-24.

ROZIK, Eli (2000): "Is the Notion of «Theatricality» Void?", Gestos, 30 (noviembre), pp. 11-30.

SCHECHNER, Richard (2002): Performance Studies. An Introduction, London/New York, Routledge.

TAYLOR, Diana y Juan VILLEGAS, eds. (1994): Negotiating Performance: Gender; Sexuality and Theatricality in Latin/o America, Durham and London, Duke University Press.

TURNER, Victor (1969): The Ritual Process: Structure and Anti-Structure, Chicago, Aldine Publishing Company.

- (1982): From Ritual to Theatre, New York, Performing Arts Journal Publications.

VAN REIJEN, Willem (1994): Die authentische Kritik der Moderne, München, Fink.

VILLEGAS, Juan (1996): "De la teatralidad como estrategia multidisciplinaria”, Gestos, 21, pp. 7-19. (Monographic Issue "Theatricality as Multidisciplinary Strategy"). 